\title{
Catastrophic Health Expenditures And Impoverishment In Kenya
}

\author{
Diana N. Kimani, PhD \\ Mercy G. Mugo, PhD \\ Urbanus M. Kioko, PhD \\ School of Economics, University of Nairobi
}

doi: 10.19044/esj.2016.v12n15p434 URL:http://dx.doi.org/10.19044/esj.2016.v12n15p434

\begin{abstract}
Background: Out-of-pocket health expenditures leave households exposed to the risk of financial catastrophe and poverty whenever they entail significant dissaving or the sale of key household assets. Even relatively small expenditures on health can be financially disastrous for poor households and similarly, large health care expenditures can lead to financial catastrophe and bankruptcy for rich households.
\end{abstract}

Objective: There is increasing evidence that out-of-pocket expenditures act as a financial barrier to accessing health care, and are a source of catastrophic expenditures and impoverishment. This paper estimates the burden of out-of-pocket payments in Kenya; the incidence and intensity of catastrophic health care expenditure and impoverishment in Kenya.

Methods: Using Kenya Household Health Expenditures and Utilization Survey data of 2007, the study uses both descriptive and econometric analysis to investigate the incidence and intensity of catastrophic health expenditures and impoverishment as well as the determinants of catastrophic health expenditures. To estimate the incidence and intensity of catastrophic expenditures and impoverishment, the study used both Wagstaff and van Doorslaer, (2002) and $\mathrm{Xu}$ et al. (2005) and applied various thresholds to demonstrate the sensitivity of catastrophic measures. For determinants of catastrophic health expenditures, a logit model was employed.

Findings: Among those who utilized health care, 11.7 percent experienced catastrophic expenditures and 4 percent were impoverished by health care payments. In addition, approximately 2.5 million individuals were pushed into poverty as a result of paying for health care. The poor experienced the highest incidence of catastrophic expenditures.

Conclusion: The paper recommends that the government should establish avenues for reducing the burden of out-of-pocket expenditures borne by households. This could be through a legal requirement for everyone to 
belong to a health insurance and targeting the poor, the elderly and chronically ill through the devolved system of the government and devolved funds.

Keywords: Out-of-Pocket Expenditures; Catastrophic Health Expenditures; Impoverishment; Kenya

\subsection{INTRODUCTION}

The primary goal of a country's health care systems is to ensure that its population has access to high quality care. In trying to achieve this goal, some countries, Kenya included, have entrenched the right to health in their constitution. The health systems should however, ensure that as they pursue the goal, households are protected from incurring health care expenditure that is so high that it adversely affects their economic wellbeing.

According to World Health Organization (WHO, 2000), direct outof-pocket (OOP) payment for health at point of service is considered an inequitable means of financing a health system. There is often the danger of burdening different social sub-groups unequally especially the poor, women and the elderly. In such a health system, households bear the greatest financial burden and this can give rise to avoidance of necessary care or delay in seeking health care. Therefore, Payment for health care, especially catastrophic expenditure, can be a significant additional source of poverty (Baeza and Packard, 2006; Van Doorslaer et al., 2006; Wagstaff and Van Doorslaer, 2002)

Catastrophic expenditure is "any health expenditure that threatens a household's financial capacity to maintain its subsistence needs and does not necessarily equate to high health care costs. Even relatively small expenditures on health can be financially disastrous for poor households" ( $\mathrm{Su}$ et al., 2006, pp 21), forcing them to reduce expenditure on basic items. Likewise, large health care expenditures can lead to financial catastrophe and bankruptcy even for rich households (Xu et al., 2007).

According to Kenya National Health Accounts, out-of pocket expenditures as percentage of total health expenditure accounted for 54 percent in 2001/2002, 39.3 percent in 2005/2006, 36.7 percent in 2009/2010, and 40 percent in 2012/13 (Republic of Kenya, 2007; 2010; Ministry of Health, 2015). The share of OOP expenditures to total health expenditures has been decreasing between 2002 and 2010 but increased by three percentage points in 2013. Forty percent being financed from households is quite high bearing in mind the poverty levels in Kenya. In 2005, 47 percent of the population was living below the poverty line (World Bank, 2008). Since 2005, no other nationally representative household budget survey has 
been conducted to measure poverty ${ }^{5}$ and therefore it is hard to tell how poverty has changed since then. However, World Bank projects that Kenya's poverty rate is in the range of 34 and 42 percent (World Bank, 2013).

To address the challenge of high out-of-pocket expenditures, the Kenyan government attempted to introduce National Social Health Insurance Fund (NSHIF) and the 10/20 policy with the aim of reaching the poor. NSHIF aimed at expanding coverage and benefit package of the current National Hospital Insurance Fund (NHIF). Under the 10/20 policy the fee charged at government dispensaries and health centres was Kshs 10 and Kshs 20 respectively. Children aged below five years with specific health conditions such as Malaria and Tuberculosis were exempted from payment. However, NSHIF was never implemented and the 10/20 policy did not achieve its objectives. A review of 10/20 policy by Chuma et al., (2009), though conducted in only two districts, indicated that adherence to the policy was poor in both districts with drug shortage, declining revenue, poor policy design and implementation processes being the main reasons for the poor adherence. The government efforts notwithstanding, access to health care in Kenya remains a challenge. The Kenya Household Health expenditure and Utilization Survey of 2007 found that 17 percent of those who needed health care services could not access the services from both government and private facilities largely due to financial constraints.

There are two common approaches for measuring catastrophic expenditure. The first method is by Wagstaff and Van Doorslaer (2002) is in relation to budget share and the second method is by $\mathrm{Xu}$, et al., (2005), in relation to a household's capacity to pay. They define household's capacity to pay as remaining income after basic subsistence needs have been met. However, these definitions ignore variation in the capacity of households to cope with health care costs (savings, assets, credit and transfers from friends and relatives) (Flores et al., 2008). The weaknesses notwithstanding the two methods provide important measures of catastrophic health expenditure. Moreover, these measures are also useful in making comparisons across societies or countries. Many studies have used these methods to measure the incidence and extent of catastrophic OOP health expenditures (Cavagnero et al., 2006; Lee, 2011; Su et al., 2006; Mendola et al., 2007; O’Donnel et al., 2005; Saksena et al., 2006; van Doorslaer et al., 2007; Wagstaff and van

\footnotetext{
${ }^{5}$ The 2015/16 Kenya Integrated Household Budget survey (KIHBS) is ongoing in all the 47 Counties. The Survey will run for 12 months from September, 2015 to $30^{\text {th }}$ August, 2016.
} 
Doorslaer, 2002; Xu et al., 2003, 2006, 2006a and 2007; Chuma and Maina, 2012; Perkins et al., 2009; Gakidou et al., 2006; Galarraga et al., 2010; Knaul et al., 2006; Lamiraud et al., 2005; Limwattananon et al., 2007; Wagstaff 2007; Ekman, 2007 and Barasa et al., 2012). All these studies have shown that out-of-pocket expenditures lead to catastrophic spending and are major causes of impoverishment.

While most of these studies have been conducted in Asia and Latin America, a few others (Su et al., 2006; Saksena et al., 2006; Xu et al., 2006a; Chuma and Maina, 2012; Perkins et al., 2009; Ekman, 2007 and Barasa et al., 2012) have been done in Africa. Though a few of these studies have been done in Kenya, some such as Perkins et al., 2009 and Barasa et al., 2012 are plagued by problems such as unrepresentative samples, out-of-pocket costs associated with hospital admissions only and/or maternity care. Hence they do not give the true picture of catastrophic health expenditures and impoverishment in Kenya.

Impoverishment captures how far people are pushed below the poverty line as the result of health spending, and the possibility that health spending may push households who are already poor even further into poverty. Literature provides two methods for measuring impoverishment. According to Wagstaff and Van Doorslaer 2002 and Van Doorslaer et al., (2007), the difference between poverty estimates derived from household resources gross and net of OOP payments for health care may be interpreted as a rough approximation of the impoverishing effect of such payments. $\mathrm{Xu}$ et al. (2005) indicate that a non-poor household is impoverished by health expenditures when it becomes poor after paying for health services. Therefore, a household is impoverished when household expenditure is equal to or higher than subsistence spending but is lower than subsistence spending net of out-of-pocket health expenditures.

The background has demonstrated that OOP expenditures are a burden to the households and though government has implemented some policies in bid to address this burden, the initiatives have not yielded fruit since the problem still persists. This begs the question whether if the incidence and intensity of catastrophic health expenditures as well as their impoverishing effects are known, would it lead to better and more precise policy recommendations that would help address the problem? The studies cited above which have estimated the incidence of catastrophic health expenditures and impoverishment have used either of the methodologies and not both. This paper adds to the existing literature by estimating catastrophic health expenditures and impoverishment using both methodologies. By using both methodologies one can compare results with studies which used either of the methodology. The paper then explores population characteristics associated with catastrophic health expenditures across quintiles, as the basis 
for assessing the policy options available to reduce the incidence of financial catastrophe.

\subsection{METHODOLOGY AND DATA \\ 2.1 Methodology}

This section briefly discusses three methodologies. The first two methodologies (2.1.1 and 2.1.2) are for analyzing incidence of catastrophic health expenditures and impoverishment. For detailed descriptions of the methodologies see Wagstaff and van Doorslaer, (2002) and Xu et al., (2005). In these methodologies the incidence of catastrophic payments is defined as out-of pocket expenditures exceeding a threshold budget share. The two commonly used thresholds are 10 percent of total income or 40 percent of non-food income. Xu et al. use 40 percent of capacity to pay. We begin by discussing Wagstaff and van Doorslaer, (2002) methodology followed by Xu et al. (2005) methodology.

The third methodology (2.1.3) is for estimating determinants of catastrophic health expenditures. Identifying factors that are significant in explaining catastrophic expenditures is an important exercise for policy advice. While incidence informs us of the extent of catastrophic expenditures, it may not be informative enough for policy direction.

\subsubsection{Wagstaff and van Doorslaer Methodology}

To calculate catastrophic expenditure head count which is the percentage of households incurring catastrophic expenditures, define $T_{i}$ to be OOP health expenditures for household $i, x_{i}$ total expenditure for household $i$, and $f(x)$ food expenditure. A household is said to have incurred catastrophic payments if $T_{i} / x_{i}$, or $T_{i} /\left[x_{i}-f(x)\right]$ exceeds a specified threshold, $z$.

The headcount does not reflect the amount by which households exceed the threshold. We therefore use the catastrophic expenditure overshoot which captures the average degree by which health expenditures (as a proportion of total expenditure or non-food expenditure) exceed the threshold $z$. The overall overshoot $\mathrm{O}_{\mathrm{i}}=E_{i}\left(\left(T_{i} / x_{i}\right)-z\right)$.

The incidence and the intensity of catastrophic expenditures are related through the mean positive overshoot (MPO) which captures the intensity of occurrence of catastrophic expenditures defined as overshoot divided by headcount:

Standard methods of measuring poverty do not take into account OOP payments for health care. If extreme, OOP expenditures could lead to poverty. Wagstaff and van Doorslaer, (2002) describe methods to adjust poverty measures on the basis of household expenditure net of OOP spending on health care. The three measures of poverty include; 1) Poverty head count, which is the proportion of households living below the poverty 
line; 2) Poverty gap, referring to the aggregate of all shortfalls from the poverty line; and 3) Normalised poverty gap obtained by dividing the poverty gap by the poverty line. Calculating the three measures requires setting a poverty line and assessing the extent to which health care payments push households below the poverty line. The official national poverty line for Kenya is Kshs. 1257 per person per month and this was used in this paper to estimate poverty levels before and after health care payments. The difference between the relevant poverty measures before and after paying for healthcare is the poverty impacts of out-of-pocket payments.

\subsubsection{Xu et al. Methodology}

$\mathrm{Xu}$ et al. (2005) estimate catastrophic health expenditures based on capacity to pay. The methodology requires data on out-of-pocket health expenditure (OOP), household consumption expenditure (exp), food expenditure (food), poverty line (pl) and household subsistence spending (se), the household's capacity to pay (ctp).

Out-of-pocket health expenditures refer to payments made by households at the time of receiving health services. They include doctors' consultation fees, purchases of medication and hospital bills. In addition, insurance reimbursements are deducted from out-of-pocket expenditures.

Household consumption expenditure comprises both monetary and in-kind payment on all goods and services (excluding health care services), and the money value of the consumption of home-made products. Household food expenditure is the amount spent on all foodstuffs by the household plus the value of family's own food production consumed within the household. However, it excludes expenditure on alcoholic beverages, tobacco, and food consumption outside the home (e.g. hotel and restaurants).

The methodology uses adult equivalent household size rather than actual household size. The reason for equivalising is to put them on a comparable basis considering that a lone adult does not require the same food expenditure as a family of four. Considering that the poorer the household the higher the share of total income or consumption devoted to food (Xu et al., 2003), calculations of subsistence expenditures and poverty line are based on the average food expenditure of households whose food expenditure share of total expenditures is in the 45-55 percentile range. This gives the subsistence expenditure per (equivalent) capita, which is also the poverty line. The subsistence expenditure for each household is then the poverty line multiplied by the equivalised household size. If total household expenditure is smaller than the subsistence spending of a household it is then regarded as poor.

Household capacity to pay is then defined as a household nonsubsistence spending. Food expenditure may be lower than subsistence 
spending for some households implying that the household's food expenditure is under the estimated poverty line. This could be as a result of the fact that reported food expenditure in the survey does not consider food subsidies, self-production and other non-cash means of food consumption. In that case, the non-food expenditure is used as non-subsistence spending.

The burden of health expenditures is defined as the out-of-pocket expenditures as a percentage of a household's capacity to pay. Catastrophic heath expenditure occurs when a household's total out-of-pocket health expenditures equal to or exceed 40 percent of household's capacity to pay or non-subsistence spending ( $\mathrm{Xu}, 2005)$. Catastrophic health expenditure is a dummy variable taking on the value 1 if a household has catastrophic expenditure, and 0 without catastrophic expenditure.

A non-poor household is impoverished by health expenditures when it becomes poor after paying for health services. Impoverishment variable takes on the value of 1 when household expenditure is equal to or higher than subsistence spending but is lower than subsistence spending net of out-ofpocket health expenditures, and 0 otherwise.

\subsubsection{A Logit Model of determinants of Catastrophic Expenditure}

Following other studies in the literature, the logistic regression model is applied to the analysis of determinants of catastrophic health expenditure. The unit of analysis is the household. The dependent variable is occurrence of catastrophic expenditure (cata) defined as 1 when the household faces catastrophic health payments, and 0 otherwise. Based on the logistic distribution function, the probability of a household facing catastrophic expenditure is:

$\operatorname{Pr}($ cata $=1 \mid X)=F\left(X^{\prime} \beta\right)=e^{X^{\prime} \beta} /\left(1+e^{X^{\prime} \beta}\right)$

The associated odds ratios can be written as follows:

$O R=\frac{P}{1-P}=\frac{\operatorname{Pr}(\text { cata }=1 \mid X)}{\operatorname{Pr}(\text { visit }=0 \mid X)}=e^{x^{\prime} \beta}$

The odds ratios formulation is relevant if the only data available for estimation are at the group rather than individual level. In the event of individual level data, the probability of experiencing catastrophic health expenditures is determined by an underlying latent variable, $\mathrm{y}^{*}$, with a dichotomous realization on the dependent variable. The dependent variable, cata, is measured as follows:

$$
\begin{aligned}
& y_{i}= \begin{cases}1 & \text { if } y_{i}^{*}>0 \\
0 & \text { if } y_{i}^{*} \leq 0\end{cases} \\
& y^{*}=\sum X^{*} \beta+\varepsilon
\end{aligned}
$$


$\varepsilon$ is a random error term assumed to follow a logistic distribution. $\mathrm{X}$ is a set of independent variables which, in our case, include insurance cover, inpatient and outpatient health care utilization, area of residence, log of expenditure, household size, household head's characteristics (such as education level, working status and gender), chronic illness, having household members aged 65 years and above (senior), and children below five years. The model is estimated by maximum likelihood.

\section{$2.2 \quad$ Data}

The study used data from the 2007 Household Health Expenditure and Utilization Survey (HHE\&US). The survey was conducted by the Kenya National Bureau of Statistics for the Ministry of Health in September and October 2007. The survey sought information on the household's demographics, health situation, health care utilization, health expenditures and other households' expenditures, and household income and assets. The survey covered all provinces and districts of the country. The total sample was 8,844 households $(2,772$ urban and 6,072 rural) yielding a sample of 38,317 individuals.

Table 1: Definition and Measurement of Variables.

\begin{tabular}{|c|l|l|}
\hline Variable name & Measurement & Apriori signs \\
\hline $\begin{array}{c}\text { Catastrophic } \\
\text { health expenditure }\end{array}$ & $\begin{array}{l}1 \text { if a household experiences a catastrophic health } \\
\text { expenditure; 0 otherwise }\end{array}$ & $\ldots$ \\
\hline Insurance cover & $\begin{array}{l}1 \text { if a household has some form of insurance cover (either } \\
\text { private or NHIF); 0 otherwise }\end{array}$ & Negative \\
\hline Inpatient & $\begin{array}{l}1 \text { if a member of household was an inpatient within one } \\
\text { year prior to survey; 0 otherwise }\end{array}$ & Positive \\
\hline Outpatient & $\begin{array}{l}1 \text { if a household member visited a health facility or doctor } \\
\text { one month prior to the survey; 0 otherwise }\end{array}$ & Positive \\
\hline Area of residence & 1 if the household is located in an urban area; 0 otherwise & Negative \\
\hline $\begin{array}{c}\text { Log of } \\
\text { expenditure }\end{array}$ & The natural log of household monthly expenditure & Negative \\
\hline Household size & Number of members in the household & Positive \\
\hline $\begin{array}{c}\text { Male headed } \\
\text { household }\end{array}$ & 1 if the head of household is a male; 0 otherwise & Negative \\
\hline $\begin{array}{c}\text { Household head } \\
\text { education level }\end{array}$ & $\begin{array}{l}1 \text { if the head of household has secondary school level of } \\
\text { education and above; 0 otherwise }\end{array}$ & Negative \\
\hline Chronic illness & $\begin{array}{l}1 \text { if a member of household has a chronic illness; } \\
\text { otherwise }\end{array}$ & Positive \\
\hline Senior & $\begin{array}{l}1 \text { if a household has a member aged 65 years and above; } \\
0 \text { otherwise }\end{array}$ & Positive \\
\hline Child & $\begin{array}{l}1 \text { if a household has a child aged five years and below; 0 } \\
\text { otherwise }\end{array}$ & Positive \\
\hline $\begin{array}{c}\text { Household head } \\
\text { working status }\end{array}$ & 1 if the head of household is working; 0 otherwise & Negative \\
\hline
\end{tabular}


3.0 RESULTS

Table 2: Description of the Analytic Sample $(N=8,453)$

\begin{tabular}{|l|r|r|r|r|}
\hline Variable & Mean & Std. Dev. & \multicolumn{2}{|c|}{ Range } \\
\hline Catastrophic Expenditure & 0.112 & 0.315 & 0 & 1 \\
\hline Insurance Cover & 0.148 & 0.355 & 0 & 1 \\
\hline Child & 0.432 & 0.495 & 0 & 1 \\
\hline Senior & 0.130 & 0.336 & 0 & 1 \\
\hline Chronic & 0.244 & 0.429 & 0 & 1 \\
\hline Inpatient & 0.095 & 0.293 & 0 & 1 \\
\hline Outpatient & 0.476 & 0.499 & 0 & 1 \\
\hline Male headed household & 0.711 & 0.453 & 0 & 1 \\
\hline Educated household head & 0.323 & 0.468 & 0 & 1 \\
\hline Area of residence & 0.313 & 0.464 & 0 & 1 \\
\hline Income & 12,769 & 36,803 & 17 & $1,651,367$ \\
\hline Household size & 4.540 & 2.372 & 1 & 15 \\
\hline Working Head of Household & 0.770 & 0.421 & 0 & 1 \\
\hline Health care utilization & 0.512 & 0.500 & 0 & 1 \\
\hline
\end{tabular}

Source: Author's Computation, KHHEUS 2007.

The statistics show that out of those who sought health care, 11.17 percent experienced catastrophic health expenditures and 14.8 had some form of insurance cover. Ten percent and 47.6 percent of the respondents utilized inpatient and outpatient care respectively. On average, a household spent Ksh 12,769 per month as household expenditure. Among the household characteristics, 30.7 percent were poor, 71 percent were maleheaded households, 32 percent had an educated household head and the average household size was five members. With regard to household composition, 24 percent of the households had at least one member with a chronic illness, 13 percent with a senior member aged 65 years and above, and 43 percent had a child below five years.

\subsection{Catastrophic Health Expenditures}

The results for incidence and intensity of catastrophic health expenditures are shown in Table 3. They are defined for health expenditures as a share of total household expenditure, nonfood expenditure and capacity to pay using various threshold budget shares. 
Table 3: Incidence and Intensity of Catastrophic Health Expenditures

\begin{tabular}{|l|r|r|r|r|}
\hline Catastrophic payment measures & \multicolumn{5}{l|}{ Threshold budget share $\mathbf{~}$} \\
\hline OOP as share of total expenditure & $\mathbf{1 0 \%}$ & $\mathbf{1 5 \%}$ & $\mathbf{2 5 \%}$ & $\mathbf{4 0 \%}$ \\
\hline Headcount (\%) & 14.35 & 10.78 & 7.06 & \\
\hline Overshoot (\%) & 3.04 & 2.43 & 1.61 & \\
\hline Mean Positive Overshoot (\%) & 21.18 & 22.54 & 22.80 & \\
\hline OOP as share of nonfood expenditure & & & & \\
\hline Headcount (\%) & & 20.77 & 14.53 & 9.84 \\
\hline Overshoot (\%) & & 5.52 & 3.93 & 2.33 \\
\hline Mean Positive Overshoot (\%) & & 26.58 & 27.05 & 23.68 \\
\hline OOP as share of capacity to pay & & & & \\
\hline Headcount (\%) & & & 14.84 & 11.17 \\
\hline
\end{tabular}

Source: Author's Computation

Incidence of catastrophic expenditures decreases as the thresholds increase. As the threshold is raised from 10 percent to 25 percent of total expenditure, the estimate of the incidence of catastrophic payments falls from 14.35 percent to 7.06 percent, and the average overshoot drops from 3.04 percent of expenditure to only 1.61 percent. However, the mean positive overshoot (MPO) does not decline as the threshold is raised. At 40 percent of nonfood expenditures threshold, the incidence is 9.84 percent compared to the incidence of 11.17 percent at threshold of 40 percent of capacity to pay.

Table 4 shows incidence of catastrophic health expenditures by quintiles. For all the thresholds, the poorest had the highest number of households experiencing catastrophic health expenditures. When the threshold is set at 10 percent of total expenditure, the middle quintile had the lowest incidence but at 40 percent of nonfood expenditure and of capacity to pay, while the richest quintile had the lowest incidence of catastrophic health expenditures. This confirms O'Donnel et al. (2008) assertion that nonfood expenditure threshold may better detect catastrophic payments among the poor.

Table 2: Incidence of Catastrophic Health Expenditures by Quintiles

\begin{tabular}{|c|c|c|c|c|c|c|c|}
\hline \multirow[b]{3}{*}{ Quintile } & \multicolumn{6}{|c|}{ Wagstaff and van Doorslaer Methodology } & \multirow{2}{*}{$\begin{array}{l}\text { Xu Methodology } \\
\text { OOP as share of } \\
\text { capacity to pay }\end{array}$} \\
\hline & \multicolumn{3}{|c|}{$\begin{array}{l}\text { OOP expenditure as share } \\
\text { of total expenditure }\end{array}$} & \multicolumn{3}{|c|}{$\begin{array}{l}\text { OOP expenditure as share } \\
\text { of nonfood expenditure }\end{array}$} & \\
\hline & $10 \%$ & $15 \%$ & $25 \%$ & $15 \%$ & $25 \%$ & $40 \%$ & $40 \%$ \\
\hline Poorest & 17.74 & 13.71 & 9.44 & 28.55 & 21.72 & 16.56 & 19.7 \\
\hline Second & 13.59 & 9.2 & 5.7 & 23.09 & 14.78 & 9.26 & 12.11 \\
\hline Middle & 12.17 & 8.91 & 5.58 & 18.76 & 12.05 & 7.36 & 9.09 \\
\hline Fourth & 12.95 & 10.21 & 6.41 & 17.04 & 12.53 & 8.02 & 8.37 \\
\hline Richest & 13.72 & 10.21 & 6.47 & 14.96 & 9.98 & 6.35 & 6.53 \\
\hline
\end{tabular}

Source: Author's Computation 


\subsection{Household Impoverishment}

Out-of-pocket expenditures led to financial difficulties for some households, and pushed others into poverty. Figure 1 presents results of estimates of impoverishment using $\mathrm{Xu}$ methodology. The results show that four percent of the households who used health services were impoverished and that the highest impoverishment of 6.1 percent occurred in the middle quintile, and the lowest impoverishment in the poorest quintile. This is because they were already under the poverty line before health payments, an implication that it is households with higher total expenditure that are more likely to spend a large fraction of those resources on health care. This reflects the inability of the poorest of the poor to divert resources from basic needs.

Figure 1: Household Impoverishment by Expenditure Quintiles

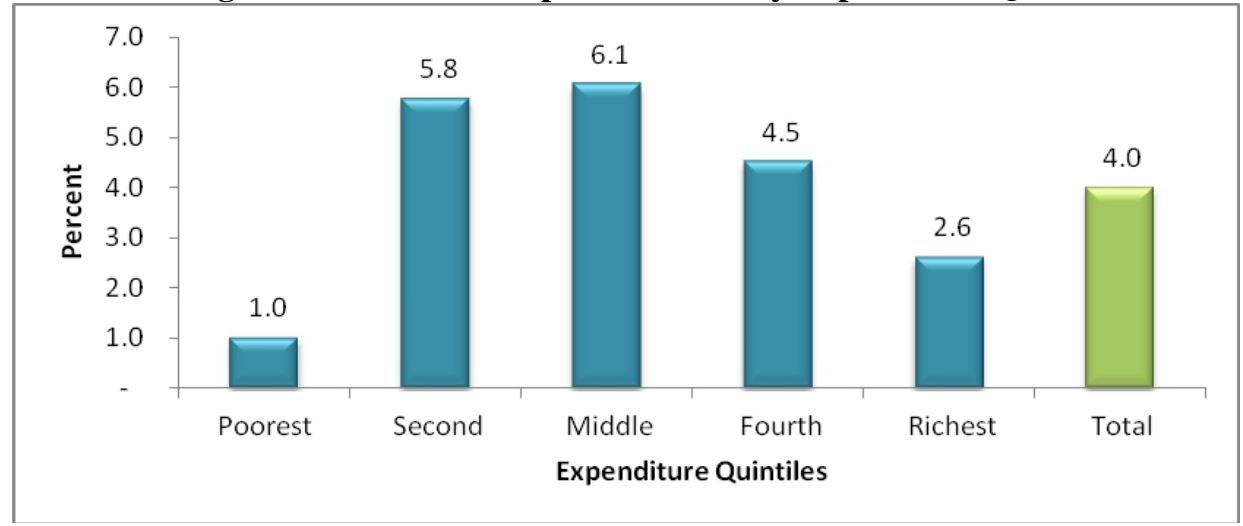

\subsubsection{Catastrophic health expenditures and impoverishment by insurance coverage}

Figure 3 shows that those who did not have any form of insurance experienced higher incidence of catastrophic health expenditures than those who had. However, having NHIF insurance does not seem to shield people from impoverishment. Indeed, those with NHIF cover experienced higher impoverishment than those who did not have. This could be explained by the limited benefit package which accompanies NHIF compared to private health insurance. On the other hand, private health insurance seems to effectively shield people from both incidences of catastrophic health expenditures and impoverishment. Only five percent and two percent of those who had private insurance experienced catastrophic health expenditures and impoverishment, respectively. 
Figure 2: Catastrophic Health Expenditures and Impoverishment by Insurance

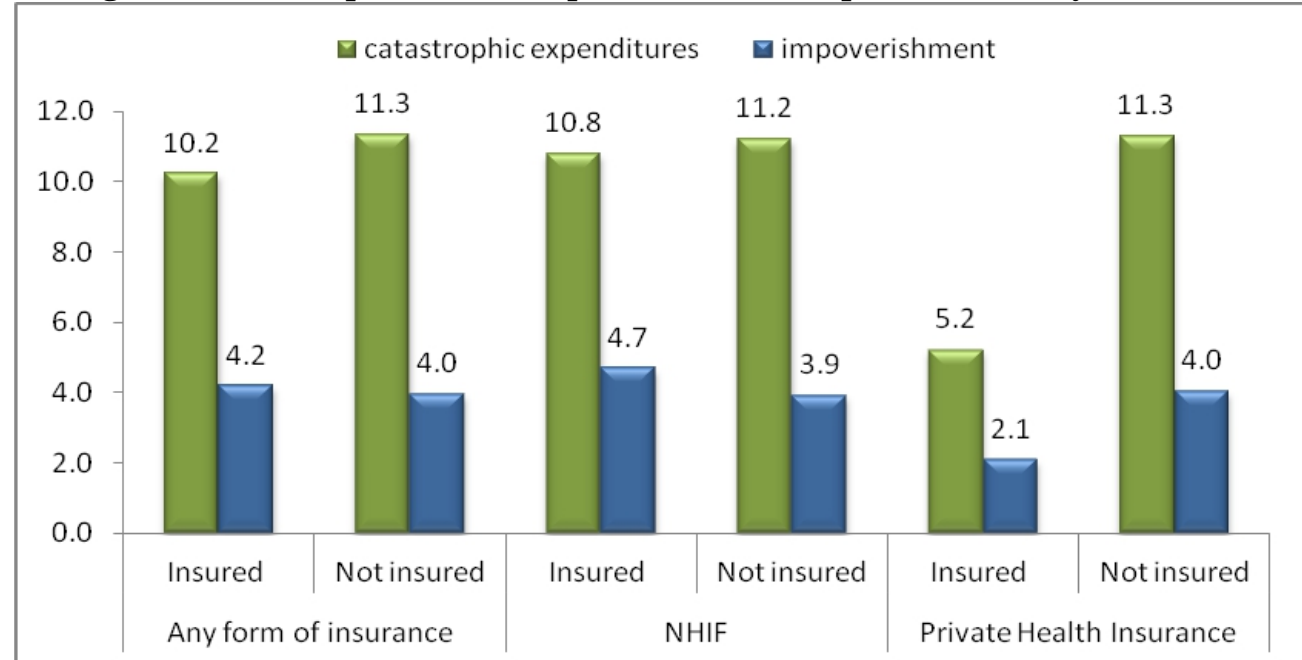

Household impoverishment was also estimated by calculating poverty levels using consumption expenditure before making health care payments and after paying for health care (Wagstaff and van Doorslaer methodology). Both the headcount and the poverty gap were calculated. The national poverty line of Ksh. 1,257 per person per month was used to estimate poverty levels before and after health care payments. Table 5 shows poverty headcount and gap before and after paying for health care.

Table 3: Poverty Headcount and Gap before and After OOP payments

\begin{tabular}{|c|c|c|c|c|}
\hline & \multirow{2}{*}{$\begin{array}{c}\text { Gross of health } \\
\text { payment } \\
\text { (1) }\end{array}$} & \multirow{2}{*}{$\begin{array}{l}\text { Net of health } \\
\text { payments } \\
(2)\end{array}$} & \multicolumn{2}{|c|}{ Difference } \\
\hline & & & $\begin{array}{c}\text { Absolute } \\
(3)=(2)-1)\end{array}$ & $\begin{array}{c}\text { Relative } \\
{[(3) /(1) * 100]}\end{array}$ \\
\hline \multicolumn{5}{|c|}{ Kshs 1257 per month poverty line } \\
\hline $\begin{array}{l}\text { Poverty headcount } \\
(\%)\end{array}$ & 49.18 & 52.28 & 3.1 & 6.3 \\
\hline Poverty Gap & 4930 & 5374 & 444 & $9 \%$ \\
\hline
\end{tabular}

Source: Author's Computations

The results show that 49.18 percent of individuals were living below poverty line before paying for health care. After paying for health care, the headcount increased by 3.1 percent. This represents an increase of 6.3 percent of population or 2.5 million individuals falling into poverty as a result of paying for health care. The average shortfall from the poverty line (the poverty gap) was Ksh 4,930 before accounting for health care payments and Ksh 5,374 after accounting for health care payments. This represents an increase in poverty gap of nine percent. Table 6 shows some sample characteristics of variables used in estimations. 


\subsection{Correlates of Catastrophic Health Expenditure}

Table 6 presents logit results for determinants of catastrophic health expenditures.

Table 4: Logit Results: Dependent Variable is Catastrophic Expenditure Dummy

\begin{tabular}{|c|r|r|r|r|r|}
\hline Variable & Odds Ratio & $\mathbf{d y} / \mathbf{d x}$ & Coef. & Std. Err. & P>IzI \\
\hline Insurance cover & 1.072 & 0.006 & 0.069 & 0.121 & 0.539 \\
\hline Child & 0.892 & -0.010 & -0.114 & 0.066 & 0.123 \\
\hline Senior & 0.929 & -0.007 & -0.074 & 0.103 & 0.506 \\
\hline Chronic & 0.956 & -0.004 & -0.045 & 0.081 & 0.599 \\
\hline Male headed household & 0.900 & -0.010 & -0.105 & 0.071 & 0.184 \\
\hline Educated household head & 0.959 & -0.004 & -0.042 & 0.086 & 0.640 \\
\hline Working household head & 1.061 & 0.005 & 0.059 & 0.092 & 0.496 \\
\hline Residence & 1.150 & 0.013 & 0.139 & 0.100 & 0.108 \\
\hline Log of income & 0.603 & -0.046 & -0.506 & 0.023 & 0.000 \\
\hline Log of household size & 1.776 & 0.052 & 0.574 & 0.143 & 0.000 \\
\hline Inpatient & 1.261 & 0.023 & 0.232 & 0.144 & 0.042 \\
\hline Outpatient & 1.197 & 0.016 & 0.180 & 0.087 & 0.013 \\
\hline Constant & 3.522 & & 1.259 & 1.127 & 0.000 \\
\hline No. of observations $=8422$ & & & Prob $>$ chi2 $=0.000$ \\
LR chi2 (12) = 241.93 & \multicolumn{1}{|l}{ Pseudo R2 $=0411$} \\
\hline
\end{tabular}

The coefficients on outpatient and inpatient care utilization are positive and statistically significant at 5 percent. This means that utilizing either outpatient or inpatient health services is positively associated with the risk of incurring a catastrophic health expenditure. Being an outpatient increases the probability of incurring catastrophic health expenditures by 0.016. On the other hand, inpatients have a .023 higher probability of incurring catastrophic health expenditure.

Income is a significant determinant of catastrophic health expenditures. The results show that increasing income by one percent reduces the probability of incurring catastrophic health expenditures by 3.5 percent. The findings suggest that households with higher incomes are less likely to incur catastrophic health expenditures than poorer households.

An increase in household size by one unit will increase the probability of incurring catastrophic health expenditures by 4.4 percent. Larger household size means higher probability of someone being ill. Moreover, if the disease is contagious, then it is more likely that more persons will be sick in a larger household. As a result, we would expect that expenditure on health care to be higher in larger households. Since larger health expenditure is more likely to result in catastrophic health expenditure, then household size is also expected to increase the probability of catastrophic health expenditure. 


\subsection{Discussion of Results}

This chapter has provided very intuitive results. First, the estimation of catastrophic health expenditures and impoverishment using $\mathrm{Xu}$ (2005) methodology shows that 11 percent of household who utilized health care incurred catastrophic health expenditures and 4 percent were impoverished. A study by Xu et al. (2006a) used Kenya Household Health Expenditure and Utilization data of 2003 and found that 10 percent of those who used health services experienced catastrophic health expenditures, and 3.5 percent were impoverished by health payments. This means that the incidence of catastrophic health expenditures increased by one percentage point in the four year period. The two studies are comparable since they both used the same Xu (2005) methodology and data collected by the same agency which ensured, as much as possible, that the same households that were interviewed in 2003 were interviewed in 2007 (Government of Kenya, 2009).

Using Wagstaff and van Doorslaer (2002) methodology, the incidence of catastrophic expenditure was found to be 14.35 percent when the threshold was set at 10 percent of total expenditure and 10 percent when the threshold was set at 40 percent of nonfood expenditure. O'Donnel et al. (2008) suggest that if health spending is income elastic, nonfood expenditure may be preferred for the denominator of the budget share to better detect catastrophic payments among the poor. The result of catastrophic incidence of 10 percent when threshold is 40 percent of nonfood expenditure is close to the result of catastrophic incidence using Xu (2005) methodology. A recent study by Chuma and Maina (2012) used the same 2007 Household Expenditure and Utilization Survey data and found that at 10 percent of total expenditure threshold, the incidence of catastrophic expenditures was 15.5 percent, and at 40 percent of nonfood expenditure threshold, the incidence was 11 percent. These findings suggest that some Kenyans bear a big burden of OOP expenditures.

The incidence of catastrophic expenditures is lower when OOP expenditures are expressed as a percent of total expenditure than of nonfood expenditure and capacity to pay. This implies that food expenditure forms a high proportion of total expenditure, and this is typical of low income countries (Chuma and Maina, 2012).

Further analysis of our findings shows that the poor are the most affected by catastrophic health expenditures. High incidence among the poor shows that OOP expenditures are regressive and there is lack of protection of the poor against such high spending. Regression results reveal that increasing income by reduces probability of incurring catastrophic expenditures, and an increase in poverty increases the probability of incurring catastrophic expenditures. The implication here is that failure to establish avenues and 
mechanisms for increasing incomes and reducing poverty will continue to push more people into poverty due to high costs of illness.

The difference between poverty estimates derived from household expenditures gross and net of OOP payments for health care correspond to the number of individuals that are driven into poverty by OOP payments. Our findings show that about 2.5 million Kenyans were pushed below the national poverty line due to OOP expenditures. The poverty gap also increased by Ksh 440, probably due to non-poor individuals falling below the poverty line and poor individuals falling further below the poverty line. The study by Xu et al. (2006a) found the poverty gap increased by Ksh 336 shillings per year in 2003 due to paying for health services. Hence, OOP expenditures are a major barrier of development. However, this finding does not provide an estimate of how poverty would change if some form of prepayment replaced OOP financing of health care. Identification of such an effect would require tracing the impact of such a reform on households' utilization of health care, work effort, consumption and savings. Nonetheless, the figure is informative of the magnitude of the impoverishing effect of payments for health care that is not currently reflected in poverty estimates. It tells us how many individuals are not counted as poor despite the fact that the value of their consumption of all goods and services, other than health care, is less than the national poverty line of Ksh 1,257 per person per month.

From the logit regression results, health insurance coverage does not appear to be a significant determinant of catastrophic expenditures in Kenya. This could be due to the limited number of Kenyans with any form of health insurance. In addition, majority of those with any form of insurance are covered by NHIF, which only covers bed costs related to inpatient stays. Therefore, a substantial part of inpatient costs as well as outpatient services is paid through OOP. The descriptive analysis shows that those with private insurance incurred less impoverishment compared to those with NHIF coverage. However, private insurance is afforded mostly by higher income earners due to the high premiums involved. Thus, it is not surprising that the current insurance has no effect on protecting households from catastrophic expenditure, although it plays a certain role in reducing some households' financial burden.

The findings on insignificance of insurance as a determinant of catastrophic health expenditures are supported by findings in Hong Kong, where private health insurance cover was not associated with the risk of catastrophic payments (O'Donnell et al., 2005). However in Thailand, the same authors found that those without cover were 40 percent more likely than those with universal coverage insurance cover to incur catastrophic payments. Therefore, significance of insurance coverage to catastrophic 
health expenditures differs from country to country depending on factors such as the depth of the coverage.

\subsection{CONCLUSION AND POLICY RECOMMENDATIONS 4.1 Conclusion}

Direct out-of-pocket expenditures at the time of care are identified as the single biggest barrier to health care access. While user fees have been promoted as a way to reduce the overuse of services, this is not what happens. User fees have adverse effects on the poor. They are inefficient, encourage people to delay seeking care until a condition is far advanced, and far more difficult and expensive to treat. And when people pay out-of-pocket for care, financial ruin is usually the result.

One important finding of this paper is that out-of-pocket expenditures cause financial catastrophe to households while others are impoverished. While this paper strongly recommends a reduced reliance on direct payments, it does not call for an immediate end to user fees. However, the removal of user fees at the primary health care is commendable. In addition, expanding the current health insurance coverage and move towards universal health insurance coverage is seen as the most effective way to shield the population from the impoverishing effects of out-of-pocket expenditures.

\subsection{Policy Recommendations}

Kenya is fairly well equipped with administrative structures under NHIF in order to expand coverage to enable the poor and the elderly to be covered. We would thus expect a continuous progress in population coverage of NHIF, with the aim of eventually reaching universal coverage. However, in the transitional period, other social protection programs such as private health insurance and community-based health insurance may need to be considered. Yet they should be well regulated and fit in the overall health financing strategy of the country, namely, moving from a system based on out-of-pocket payments to prepayment and pooling of resources.

One area that will have to receive attention is how to protect vulnerable groups from the impoverishing effects of health care expenditure. Some areas that could be considered include revisiting the user fee structure - both its design and implementation - to consider different exemption criteria, examining the constraints on the expansion of health insurance to uncovered groups, such as agricultural workers and the informally employed; and exploring the potential role of private sector providers and insurers in expanding access to care.

Our findings have shown that poverty estimates which do not account for OOP expenditures are usually grossly underestimated. It would therefore be important for future national poverty estimates to take into account health 
care payments by households as has been done in this study. This will give the nation an indication of the magnitude of household impoverishment due to out-of-pocket expenditures.

\section{References:}

Baeza, C. and Packard T. G. (2006). Beyond Survival: Protecting Households from Health Shocks in Latin America. The World Bank and Stanford University Press. Washington DC

Barasa, E. W., Ayieko P., Cleary S. and English M. (2012). Out-of-pocket costs for paediatric admissions in district hospitals in Kenya. Tropical Medicine and International Health 17(8) 958-961

Cavagnero, E. G. Carrin, K. Xu and A. M. Aguilar-Rivera (2006). Health Financing in Argentina: An Empirical Study of Health Care Expenditure and Utilization. FundaciónMexicana para la Salud, A. C. InstitutoNacional de Salud Pública, Mexico.

Chuma J. and Maina T. (2012).Catastrophic Health Care Spending and Impoverishment in Kenya.BMC Health Services Research 12:413.

Chuma J., Musimbi J., Okungu V., Goodman C. and Molyneux C. (2009). Reducing user fees for primary health care in Kenya: policy on paper or policy in practice? International Journal for Equity in Health 8, 15.

Ekman, B. (2007). Catastrophic Health Payments and Health Insurance: Some Counterintuitive Evidence From One Low-Income Country. Health Policy, 83: 304-313.

Flores G. Krinshnakumar J. O’Donnell O. van Doorslaer E. (2008). Coping with Health-Care Costs: Implications for the Measurement of Catastrophic Health Expenditures and Poverty.Health Economics 17(12). pp. 1393-1412.

Gakidou, E., Lozano R., Gonzalez-Pier E., Abbott-Klafter J., Barofsky J. T. (2006). Health System Reform in Mexico - Assessing The Effect of the 2001-06 Mexican Health Reform: An Interim Report Card. Lancet;368(9550):1920-1935.

Galarraga, O., Sandra G., Sosa-Rubi, Salinas-Rodrıguez A. Sesma-Va'zquez S. (2010). Health Insurance for the Poor: Impact on Catastrophic and OutOf-Pocket Health Expenditures in Mexico. European Journal of Health Economics 11:437-447. DOI 10.1007/s10198-009-0180-3. Springer

Knaul, F. M., Arreola-Ornelas H., Mendez-Carniado O., Bryson-Cahn C., Barofsky J, (2006). Health System Reform in Mexico - Evidence is Good for Your Health System: Policy Reform to Remedy Catastrophic and Impoverishing Health Spending in Mexico. Lancet; 368(9549):1828-1841

Lamiraud, K., Booysen F. and Scheil-Adlung X. (2005). The impact of Social Health on Access to Health Care, Health Expenditure and Impoverishment: A Case Study of South Africa. International Labour Office (ILO) Geneva. 
Lee, T. J. (2011). Paying out-of-pocket for health care in Korea: Change in catastrophic and poverty impact over a decade. Available at http://ebookbrowse.com/rp254-takemi-journal1-lee-pdf-d57080924.

Limwattananon S., Tangcharoensathien V., Prakongsai P. (2007). Catastrophic and Poverty Impacts of Health Payments: Results From National Household Surveys in Thailand. Bulletin of the World Health Organization.85(8):600-606.

Mendola, M., Bredenkamp C. and Gragnolati M. (2007). The Impoverishing Effect of Adverse Health Events: Evidence from the Western Balkans. World Bank Policy Research Working Paper Series.

Ministry of Health, (2015). Kenya National Health Accounts 2012/13. Nairobi: Ministry of Health.

O’Donnell, O., E. van Doorslaer, R. P. Rannan-Eliya, A. Somanathan, C. C. Garg, P. Hanvoravongchai, M. N. Huq, A. Karan, G. M. Leung, K. Tin, C. Vasavid, (2005). Explaining the Incidence of Catastrophic Health Expenditures on Health Care: Comparative Evidence From Asia. The World Bank, Washington, D.C

Perkins, M., Brazier E., Themmen E., Bassane B., Diallo D., Mutunga A., Mwakajonga T., Ngobola O. (2009). Out-of-pocket costs for facility-based maternity care in three African countries. Health Policy and Planning 24:289-300

Republic of Kenya, (2010). Kenya National Health Accounts 2009/10. Ministry of Medical Services and Ministry of Public Health and Sanitation.

Republic of Kenya, (2007). National Health Accounts (NHA) 2005/06. Ministry of Health

Saksena, P., Xu K. and Carrin G. (2006). The Impact of Universal Insurance Program on Catastrophic Health Expenditure: Simulation Analysis for Kenya. World Health Organization, Geneva.

Su T. T., Kouyaté B. and Flessa S. (2006). Catastrophic Household Expenditure for Health Care in a Low-Income Society: A Study from Nouna District, Burkina Faso. Bull World Health Organization vol.84 no.1

Van Doorslaer, E., O’Donnell W., Rannan-Eliya R. P., Somanathan A., Adhikari S. R., Garg C. C., Harbianto D., Herrin A. N., Huq M. N., Ibragimova S., Karan A., Lee T., Leung G. M., Lu J. R., Ng C. W., Pande B. R., Racelis R., Tao S., Tin K., Tisayaticom K., Trisnantoro L., Vasavid C. and Zhao Y. (2007). Catastrophic Payments for Health Care in Asia.Health Economics 16: 1159-1184

vanDoorslaer E., O'Donnell O., Rannan-Eliya R. P., Samanathan A., Adhikari S. R., Garg C. C., Harbrianto D., Herrin A. N., Huq M. N., Ibragimova S., Karan A., Ng C. .W, Pande B. .R, Racelis R., Tao S., Tin K., Tisayaticom K., Trisnantoro L., Vasavid C., Zhao Y. (2006). Effect of 
Payments for Health Care on Poverty Estimates in 11 Countries in Asia: An Analysis of Household Survey Data. Lancet, 368:1357-1361.

Wagstaff A. (2007). Health insurance for the Poor : Initial Impacts of Vietnam's Health Care Fund for the Poor. Impact Evaluation Series \# 11.Policy Research Working Paper \# WPS 4134.

Wagstaff and van Doorslaer (2002) Catastrophe and Impoverishment in Paying for Health Care: With Applications to Vietnam 1993-98. Health Economics, 12 (11): 921-934

World Bank, (2013). Kenya Economic Update: Time to shift gears: Accelerating growth and poverty reduction in the new Kenya. World Bank http://www.worldbank.org/kenya/keu

World Bank, (2008). Kenya Poverty and Inequality Assessment. Report No. 44190-KE. Poverty Reduction and Economic Management Unit, Africa Region. World Bank.

World Health Organization, (2000). The World Health Report 2000: Health Systems: Improving Performance, Geneva: World Health Organization.

Xu K., Evans D, B., Carrin G., Aguilar-Rivera A. M., Musgrove P. and Evans T. (2007).Protecting Households from Catastrophic Health Spending. Health Affairs 26, no. 4: 972-983

Xu, K., Carrin G., Phuong N. T. K., Long N. H., Bayarsaikhan, and Aguilar A. M. (2006). Health Service Utilization and the Financial Burden on Households in Vietnam: The Impact of Social Health Insurance. World Health Organization, Geneva.

Xu K., James C., Carrin G. and Muchiri S. (2006a). An Empirical Model of Access to Health Care, Health Care Expenditure and Impoverishment in Kenya: Learning From Past Reforms and Lessons for the Future. World Health Organization, Geneva.

Xu K. (2005). Distribution of Health Payments and Catastrophic Health Expenditures: Methodology. World Health Organization, Geneva.

Xu K., D. B. Evans, K. Kawabata, R. Zeramdini, J. Klavus, C. J. L. Murray (2003). Household Catastrophic Health Expenditure: A Multicountry Analysis. Lancet 2003; 362: 111-17 Accessed on 4th May 2010 at 4.27 pm. 